\title{
Comparative efficacy of visual inspection with acetic acid versus cytology for cervical cancer screening in Ogbomoso, Nigeria
}

\author{
Afolabi B. Abiodun ${ }^{1 *}$, Adewumi O. Durodola ${ }^{2}$, Mustapha A. Ajani ${ }^{3}$, Isaac O. Amole ${ }^{2}$, \\ Adejoke D. Abiodun ${ }^{4}$, Timothy A. O. Oluwasola ${ }^{5}$
}

\begin{abstract}
${ }^{1}$ Department of Family Medicine, Sacred Heart Hospital, Lantoro, Abeokuta Ogun State, Nigeria
${ }^{2}$ Department of Family Medicine, Bowen University Teaching Hospital, Ogbomoso, Oyo State, Nigeria

${ }^{3}$ Department of Histopathology, Babcock University, Ilishan-Remo, Ogun State, Nigeria

${ }^{4}$ Department of Psychiatry, Ladoke Akintola University of Technology Teaching Hospital, Osogbo, Osun State, Nigeria

${ }^{5}$ Department of Obstetrics and Gynaecology, College of Medicine, University of Ibadan, Ibadan, Oyo State, Nigeria
\end{abstract}

Received: 04 July 2017

Accepted: 29 July 2017

\section{*Correspondence:}

Dr. Afolabi B. Abiodun,

E-mail: abiodunben@yahoo.com

Copyright: ( ) the author(s), publisher and licensee Medip Academy. This is an open-access article distributed under the terms of the Creative Commons Attribution Non-Commercial License, which permits unrestricted non-commercial use, distribution, and reproduction in any medium, provided the original work is properly cited.

\section{ABSTRACT}

Background: Screening test for cervical cancer using visual inspection with acetic acid (VIA) has been advocated by World Health Organization as a suitable, low cost and feasible alternative modality for control of cervical cancer in resource-poor settings as compared to cytological and colposcopic screening. The need for reproducibility, accuracy and comparable efficacy will influence the acceptability of VIA as primary screening modalities for cervical cancer.

Methods: A cross-sectional comparative study conducted at BUTH. Data were obtained from 318 consenting women aged 30-65 years using a systematic random sampling method and an interviewer-administered structured questionnaire. Pap smear samples were taken followed by visual inspection with acetic acid. Using Statistical Package for Social Sciences (SPSS) version 23.0, Frequencies were obtained and Chi-square test $\left(\mathrm{X}^{2}\right)$ was used to compare rates and proportions with the level of statistical significance set at less than 0.05 .

Results: Positive results for premalignant cervical lesion was $1.3 \%$ and $4.1 \%$ for VIA and Pap smear respectively $\left(\mathrm{X}^{2}=4.52 ; \mathrm{p}=0.034\right)$. The sensitivity of VIA was $7.7 \%$ with positive predictive value of $25 \%$ while specificity was $99.0 \%$ with a negative predictive value of $96.2 \%$. The prevalence of abnormal cervical lesion in the population studied was $4.1 \%$ (95\% CI $2.2 \%-6.9 \%$ ).

Conclusions: The detection rate for pre-cancerous lesions of the cervix using VIA was significantly lower than that of Pap smear in this study. There may be needed to exercise caution in adopting VIA as primary screening modality for cervical cancer.

Keywords: Cervical cancer, Cytology, Ogbomoso, Pap smear, VIA, Visual inspection

\section{INTRODUCTION}

Screening is a secondary level of prevention which involves testing asymptomatic individuals in order to detect or exclude disorders at an early stage. ${ }^{1}$ This is exemplified in screening for, and treatment of, premalignant cervical lesions as regular participation in the conventional, cytology-based cervical cancer screening programme (Pap Smear) has contributed immensely to global prevention of cervical cancer. ${ }^{2-4}$ Pap smear test, though apparently simple, requires a large 
number of steps in preparation of an adequate smear, processing of specimen and informing patients of the results. ${ }^{5,6}$ Visual Inspection with Acetic Acid (VIA), a relatively cheaper alternative with locally-available equipment, can also provide immediate results thereby ensuring an adoption of a "see and treat" approach - an appropriate method for low-resource setting with documented difficulties in tracing females with positive Pap test. ${ }^{7-9}$

In Nigeria, there are considerable logistic challenges to implementing a systematic cytology based screening programme as there is currently no programme of mass screening for detection of cervical pathology. ${ }^{10-13}$ Cytology-based cervical cancer screening has failed in Africa because many countries in the region cannot afford the complex infrastructure required for a successful programme. ${ }^{13}$ Alternative methods like VIA followed by treatment of small precancerous lesions with cryotherapy have thus been found to be cost effective. ${ }^{7}$

VIA requires no specially-trained pathologist or sophisticated equipment and structures but rather a launching and sustaining cost that is much lower than with other methods. ${ }^{14}$ The main thrust of this study is to compare the efficacy of VIA with that of Pap smear as primary screening modalities for cervical cancer among asymptomatic women attending the general outpatients' clinic.

\section{METHODS}

The study was conducted among 318 consenting female patients, aged 30-65, attending the general outpatient clinic of BUTH. It was a cross sectional comparative study conducted between January and March 2014. Only women who have been sexually active for at least 3 years and who were within the required age group were recruited. Exclusion criteria included currently menstruating, history of previous total hysterectomy, current or past history of cervical cancer, obvious genital tract infection, puerperium and refusal of consent. Consent was equally obtained for follow up telephone call in view of possible need for additional care.

\section{Sampling method}

The respondents were selected using systematic sampling method. An average of 100 eligible patients attends the clinic per week out of which five women were taken per day. A simple random sampling was done to pick the first patient from the first four patients as the starting number of the systematic sampling technique while subsequent respondents were enrolled using the sampling fraction of four. Whenever the selected patient was not eligible to participate or declined, the next patient in line was considered. The selected patients were interviewed and those who met the inclusion criteria were recruited for the study after they had provided informed consent. An identification sticker was left on all patients' card until the completion of the study to avoid a repeat selection.

Using a structured questionnaire, we obtained information on the respondents' socio-demographic characteristics, education, marital and reproductive history, awareness of cervical screening modalities and uptake of Pap smear or any other screening methods. Cervical smears were taken using wooden (Ayre's) spatula and spread on glass slides. The smears were stained with the following reagents: Harris haematoxylin, Orange G6 (OG6), Eosin Azure 36, Graded Alcohol and Xylene. Freshly prepared $5 \%$ acetic acid was then used to stain the cervix before visual inspection.

The ethics committee of BUTH approved the study before commencement. The aims and scope of the study were properly explained to the respondents and the fact that they will receive the best level of care in the hospital irrespective of their choice in taking part in the study. All information gathered were kept confidential while participants were identified using only serial numbers. The respondents with varied degrees of positive screening test results were referred to the gynaecology clinic for appropriate management.

\section{Performing pap smear and VIA}

The same protocol was used for all patients. With the patient in lithotomy position, the cervix and vagina were exposed with the aid of a Cusco speculum lubricated with sterile water. With the squamo-columnar junction well visualised, it is scraped gently throughout its circumference using the wooden (Ayre's) spatula and the material transferred to glass slides. Two of such smears were fixed with $95 \%$ alcohol immediately and sent to the laboratory for staining. The smears were stained by the same laboratory scientist using Papanicolaou method and read by the same pathologist. A solution of 5\% acetic acid was then applied to the cervix using a cotton swab. The cervix was examined after one minute (by the clock) under a white light. The detection of any distinct acetowhite area was considered as positive result.

\section{Data management}

Frequency tables were generated for the different variables measured, and cross tabulations were done to compare the outcome variables for VIA and Pap smear. The Chi square $\left(\mathrm{X}^{2}\right)$ test was used to compare rates and proportions with a view to measuring statistical associations where they existed. The level of significance was set at p-value less than 0.05 .

\section{RESULTS}

We recruited 318 participants with the mean age of $42.1 \pm 8.8$ years. Majority of the subjects $(138,43.4 \%)$ were between age 40 to 49 years, married $(293,92.1 \%)$ 
with $14(4.4 \%)$ having no formal education while over half $(162,50.9 \%)$ had tertiary education (Table 1$)$.

Table 1: Socio-demographic characteristics of the respondents.

\begin{tabular}{|lll|}
\hline Characteristics & Frequency & $\%$ \\
\hline Age groups (in years) & & \\
\hline $20-29$ & 26 & 8.2 \\
\hline $30-39$ & 89 & 28.0 \\
\hline $40-49$ & 138 & 43.4 \\
\hline $50-59$ & 47 & 14.8 \\
\hline$\geq 60$ & 18 & 5.6 \\
\hline Marital status & & \\
\hline Married & 293 & 92.1 \\
\hline Separated /divorced & 8 & 2.5 \\
\hline Widowed & 17 & 5.4 \\
\hline Religion & & \\
\hline Islam & 33 & 10.4 \\
\hline Christianity & 283 & 89.0 \\
\hline Traditional & 2 & 0.6 \\
\hline Tribe & & \\
\hline Yoruba & 304 & 95.6 \\
\hline Ibo & 7 & 2.2 \\
\hline Hausa & 4 & 1.3 \\
\hline Other tribes & 3 & 0.9 \\
\hline Educational level & & \\
\hline No formal education & 14 & 4.4 \\
\hline Primary & 53 & 16.7 \\
\hline Secondary & 89 & 28.0 \\
\hline Tertiary & 162 & 50.9 \\
\hline & & \\
\hline & & \\
\hline & & \\
\hline & & \\
\hline & & \\
\hline
\end{tabular}

There are only 2 current and 5 passive smokers among the respondents. Concerning sexual history, majority of the respondents had sexual debut at age 20 to 24 and more than two-fifths $(137,43.1 \%)$ had multiple sexual partners. About one fifth of the respondents (19.8\%) were grand-multiparous (Table 2).

Table 2: Smoking and sexual history of the respondents.

\begin{tabular}{|lll|}
\hline Characteristics & Frequency & $\%$ \\
\hline Smoking history & & \\
\hline Ex - smoker & 3 & 0.9 \\
\hline Current smoker & 2 & 0.6 \\
\hline Passive smoker & 5 & 1.6 \\
\hline Non- smoker & 308 & 96.9 \\
\hline Sexual history & & \\
\hline Age at first intercourse & & 18.2 \\
\hline $15-19$ & 58 & 37.8 \\
\hline $20-24$ & 120 & 32.1 \\
\hline $25-29$ & 102 & 11.9 \\
\hline 30 and above & 38 & \\
\hline Number of sexual partner & & 56.9 \\
\hline One sex partner & 181 & 43.1 \\
\hline More than one sex partner & 137 & \\
\hline
\end{tabular}

Table 3: Determinant of risk factors in respondents using positive pap smear results.

\begin{tabular}{|c|c|c|c|c|}
\hline \multirow[b]{2}{*}{ Variables } & \multicolumn{2}{|c|}{ Cervical Dysplasia } & \multirow[b]{2}{*}{$\begin{array}{l}\text { Chi- } \\
\text { square }\end{array}$} & \multirow[b]{2}{*}{$\begin{array}{l}\text { p- } \\
\text { value }\end{array}$} \\
\hline & $\begin{array}{l}\text { Present } \\
(\%)\end{array}$ & $\begin{array}{l}\text { Absent } \\
(\%)\end{array}$ & & \\
\hline \multicolumn{5}{|c|}{ Age groups (in years) } \\
\hline $20-29$ & $2(15.4)$ & $24(7.9)$ & & \\
\hline $30-39$ & $2(15.4)$ & $87(28.5)$ & 6.42 & 0.491 \\
\hline $40-49$ & $7(53.8)$ & $131(42.9)$ & & \\
\hline $50-59$ & $1(7.7)$ & $46(15.1)$ & & \\
\hline$\geq 60$ & $1(7.7)$ & $17(5.6)$ & & \\
\hline \multicolumn{5}{|c|}{ Marital status } \\
\hline Married & $10(76.9)$ & $283(92.8)$ & 9.4 & 0.009 \\
\hline Separated & $2(15.4)$ & $6(2.0)$ & & \\
\hline Widowed & $1(7.7)$ & $16(5.2)$ & & \\
\hline \multicolumn{5}{|c|}{ Educational level } \\
\hline $\begin{array}{l}\text { No Formal } \\
\text { Education }\end{array}$ & $0(0.0)$ & $14(4.6)$ & & \\
\hline Primary & $2(15.4)$ & $51(16.7)$ & 0.67 & 0.88 \\
\hline Secondary & $4(30.8)$ & $85(27.9)$ & & \\
\hline Tertiary & $7(53.8$ & $155(50.8)$ & & \\
\hline \multicolumn{5}{|c|}{ Smoking history } \\
\hline Ex-smoker & $0(0.0)$ & $3(1.0)$ & & \\
\hline $\begin{array}{l}\text { Current } \\
\text { smoker }\end{array}$ & $0(0.0)$ & $2(0.5)$ & 0.44 & 0.932 \\
\hline $\begin{array}{l}\text { Passive } \\
\text { smoker }\end{array}$ & $0(0.0)$ & $5(1.6)$ & & \\
\hline $\begin{array}{l}\text { Non- } \\
\text { smoker }\end{array}$ & $13(100.0)$ & 295(96.7) & & \\
\hline \multicolumn{5}{|c|}{ Coitarche (age in years) } \\
\hline $15-19$ & $3(23.1)$ & $55(18.0)$ & 1.25 & 0.741 \\
\hline $20-24$ & $3(23.1)$ & $117(38.4)$ & & \\
\hline $25-29$ & $5(38.4)$ & $97(31.8)$ & & \\
\hline$\geq 30$ & $2(15.4)$ & $36(11.8)$ & & \\
\hline \multicolumn{5}{|c|}{ Number of pregnancy } \\
\hline $1-3$ & $4(30.8)$ & $152(49.8)$ & & \\
\hline$\geq 4$ & $9(69.2)$ & $153(50.2)$ & 1.83 & 0.401 \\
\hline \multicolumn{5}{|c|}{ Number of children } \\
\hline $1-3$ & $5(38.5)$ & $184(60.3)$ & & \\
\hline$\geq 4$ & $8(61.5)$ & $121(39.7)$ & 2.69 & 0.261 \\
\hline \multicolumn{5}{|c|}{ Number of sexual partners } \\
\hline 1 & $7(53.8)$ & $174(57.0)$ & & \\
\hline$>1$ & $6(46.2)$ & $131(43.0)$ & 0.052 & 0.819 \\
\hline
\end{tabular}

Concerning the practice of cervical cancer screening by the respondents, only $5(1.6 \%)$ of them have ever had screening done and they all had Pap smear in a teaching hospital. For those who were never screened, $81.8 \%$ said they never aware of cervical cancer screening service.

Prevalence of cervical dysplasia among respondents using VIA and Pap smear is as depicted in figures 1 and 2 respectively. Of the 318 respondents, only 2 had a positive VIA result therefore giving the prevalence of $1.3 \%$ using the VIA method while 13 had a positive Pap smear result with the prevalence of $4.1 \%$ using the Pap smear method. It is noted that 9 of the $13(69.2 \%)$ have 
low grade intraepithelial neoplasia according to the 2001 Bethesda classification (Figure 3).

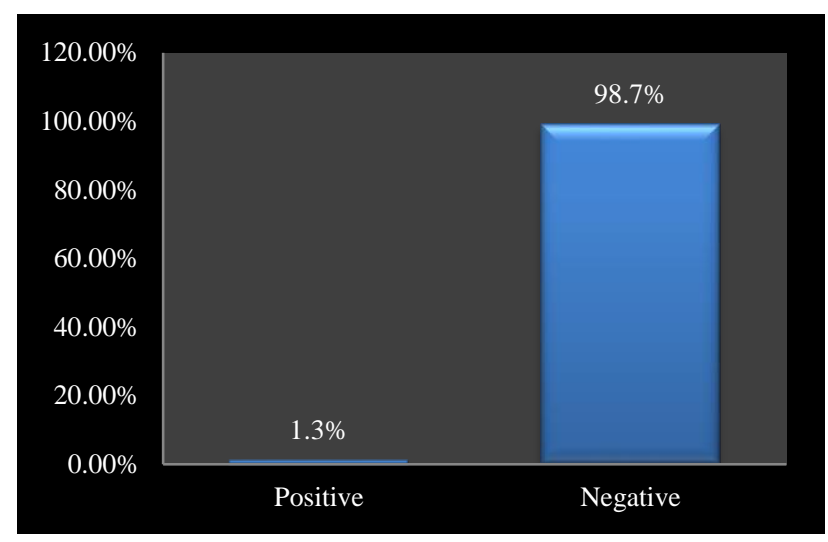

Figure 1: Prevalence of cervical dysplasia among respondents using VIA.

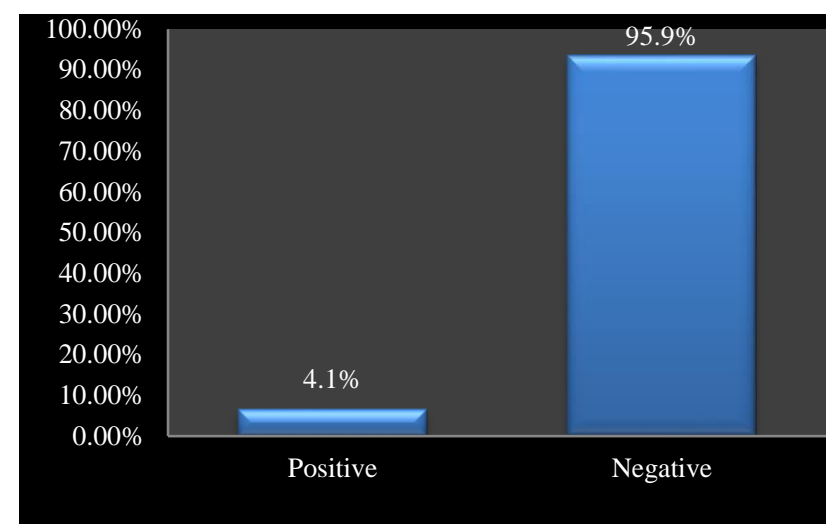

Figure 2: Prevalence of cervical dysplasia among respondent using pap smear.

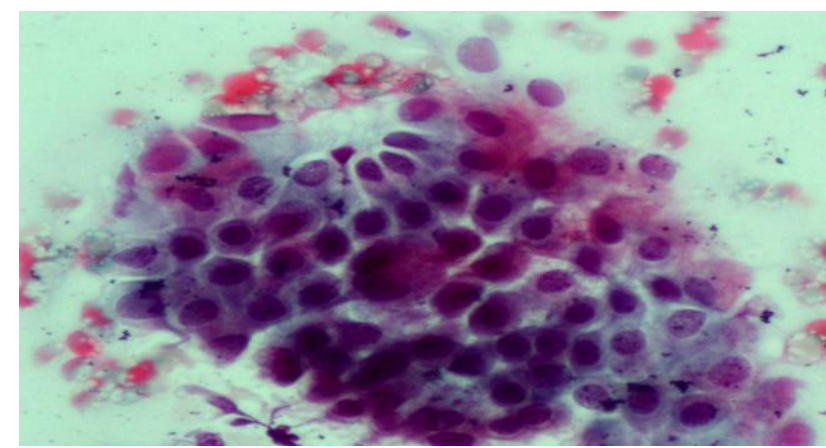

Figure 3: Photomicrograph showing anisonucleosis, hyperchromasia and nucleomegaly of squamous epithelial cells. These features are consistent with a Low grade squamous intraepithelial lesion.

(Conventional Pap smear stain, X400).

Table 3 illustrates the relationship between the risk factors in respondents and their Pap smear results. The peak age prevalence of abnormal cervical smear was 40 to 49 years $(7,53.8 \%)$.
There was a significant relationship between marital status and positive Pap smear result but not in the educational status, number of partners or number of pregnancies.

Table 4: Association between VIA and pap smear.

\begin{tabular}{|lllll|} 
VIA Result & \multicolumn{2}{l}{ Pap smear Result } & $\begin{array}{l}\text { Chi- } \\
\text { square }\end{array}$ & $\begin{array}{l}\text { p- } \\
\text { value }\end{array}$ \\
& $\begin{array}{l}\text { Positive } \\
(\%)\end{array}$ & $\begin{array}{l}\text { Negative } \\
(\%)\end{array}$ & & \\
\hline Positive(\%) & $1(7.7)$ & $3(1.0)$ & 4.52 & 0.034 \\
\hline Negative(\%) & $12(92.3)$ & $302(99.0)$ & & \\
\hline
\end{tabular}

Table 4 shows the VIA results given the respondent's risk for cervical dysplasia as determined by Pap smear results. Thirteen $(4.1 \%)$ and four $(1.3 \%)$ of the respondents had positive Pap smear results and positive VIA results respectively. There was statistically significant association $(\mathrm{p}=0.034)$ between Pap smear and VIA results of respondents in relation to the ability to detect cervical dysplasia as more than $90 \%$ of cervical dysplasia was missed using VIA alone. Pap smear was more sensitive in detecting respondents with cervical dysplasia as compared to the VIA method.

The sensitivity of VIA was $7.7 \%$ with positive predictive value of $25 \%$ while the specificity was $99 \%$ with a negative predictive value of $96.2 \%$. The prevalence of abnormal cervical lesion in the population studied was $4.1 \%(95 \%$ CI $2.2 \%-6.9 \%)$.

\section{DISCUSSION}

This study involved 318 asymptomatic women attending the General Outpatient Clinic of BUTH. It evaluated the effectiveness of VIA compared to Pap smear as screening methods for cervical cancer precursor lesions in a lowresource setting. Majority $(75 \%)$ of the participants were within the age 30 and 49 years, with a mean age of $42.1 \pm$ 8.8 years. This is the age group where pre-neoplastic lesions of the cervix have been said to be common, and they represent the productive, sexually active and reproductive and age group of the nation. ${ }^{15-17}$ Therefore, there is need to focus on this age group for cervical cancer screening to ensure a healthy and economically viable nation. The mean age of the women's sexual debut in this study was $23.4 \pm 4.8$ years. This mean age of sexual debut is similar to the report of Awodele et al in a similar study conducted in Lagos, Nigeria. ${ }^{17}$

Present study found a significant relationship between being married and having a positive cytology result but there was no significant relationship between educational status, smoking history, number of partners and number of pregnancies and parity, a major deviation from what was obtained in similar studies in this environment. Most studies in this environment had previously shown a statistically significant relationship between these risk factors and cervical dysplasia. ${ }^{18,19}$ However, these studies 
were conducted among hospital-based HIV positive and urban slum dwellers with early age at sexual debut, little or no formal education, high parity and high prevalence of other risks factors for developing cervical cancer. ${ }^{18-21}$ The difference in the findings of these studies may be due to the fact that this study was conducted among women with relatively low prevalence of the risks for developing cervical cancer. Their high education and high socioeconomic status may not reflect the true status in the community, hence complementary community based studies may be needed to give the complete and perfect picture among women in the community.

\section{Comparison of VIA and pap smear cervical dysplasia detection rates}

Of the 318 women screened, cervical dysplasia detection rate with VIA was $1.3 \%$ which differs significantly from studies in the same environment and other developing countries but agree with the low prevalence of $0.98 \%$ found in a study of Jewish women. ${ }^{7,22-24}$ The VIApositivity rates noted in the published studies from other regions and in some developing countries ranged from $5.7 \%$ to $28.0 \% .^{7,9,22-27}$ The wide variation in rates in the various studies may be due to different criteria and different cadres of health personnel used for screening and the different populations. ${ }^{28,29}$ It may also depend on the study population, since few studies were done on symptomatic hospital based population, health workers and others as a mass screening test. ${ }^{7,9,22-26}$ The inherent variability of the appearance of the cervix may have led to different subjective interpretations of the results among different health workers.

It was noted that $4.1 \%$ of Pap smears in this study were abnormal using the Bethesda system of classification. ${ }^{3}$ This result is similar to the findings from other studies in Nigeria and other developing countries. The Pap smearpositive rates noted in published studies within our local environment ranged between $3.1 \%$ and $10.0 \% .^{9,22,26,27}$ With Denny et al reporting an incidence of $8.2 \%$ for abnormal Pap smear in South Africa. ${ }^{30}$ In comparison of the diagnostic values of VIA with Pap smear, VIA seems to have a lower pre-cancerous lesion detection rate in this study. More than $90 \%$ of squamous intraepithelial lesions (SIL) were missed using VIA alone while one case of cervical cancer missed by VIA was detected by Pap smear. It should be noted that central to the success of any screening programme is its entirety in functioning which requires the ability of such programme to ensure high levels of coverage of target population, offer high quality and caring services, develop and monitor good referral systems that ensure good patient follow-up and ensure that the patients receive appropriate, acceptable and caring treatment in the context of informed consent. ${ }^{20,21}$

In conclusion therefore, it has been confirmed that the detection rate for pre-cancerous lesions of the cervix using the VIA was significantly lower than that of the
Pap smear in this study which confirmed that Pap smear performed significantly better than VIA in detecting precancerous lesion of the cervix although VIA has been introduced as an alternative testing method for cervical pre-malignant lesions in low-resource countries because of the high incidence of, and mortality from, cervical cancer. ${ }^{7,13,29}$ However, with the findings of this study, there may be need to exercise caution in the adoption of VIA as primary screening modality for cervical cancer. There may be need for more broad-based researches, training and retraining of health workers before a final decision will be taken.

Currently, cervical cytology is widely regarded as the gold standard for cervical cancer screening in all developed countries. ${ }^{9}$ There are considerable logistic challenges to implementing a systematic cytology based screening programme in a country like Nigeria. ${ }^{12}$ There is therefore a need to develop low cost screening strategies for cervical cancer which will necessarily involve the use of simple technique that can be easily taught and practiced by all medical and paramedical personnel especially in the rural areas. ${ }^{13}$

Limitations of the study was to our inability to take cervical biopsy for definitive diagnosis was an identified limitation although our main aim was to compare the effectiveness of VIA with cervical cytology in order to adopt the suggestion of its use for mass screening. In addition, this study was hospital-based and will therefore require a complementary community-based studies in order to have a robust picture of the use of VIA among women in the community.

\section{Funding: No funding sources}

Conflict of interest: None declared

Ethical approval: The study was approved by the Institutional Ethics Committee BUTH

\section{REFERENCES}

1. National Cancer Intelligence Network (NCIN). Cervical cancer screening. NCIN Report. 2013;9-10.

2. WHO. Comprehensive Cervical Cancer Control: A Guide to Essential Practice. 2006 p. 123-4.

3. Dim CC. Towards improving cervical cancer screening in Nigeria: A review of the basics of cervical neoplasm and cytology. Nigerian Journal of Clinical Practice. 2012. p. 247-52.

4. Downs LS, Smith JS, Scarinci I, Flowers L, Parham G. The disparity of cervical cancer in diverse populations. Gynecol Oncol. 2008;109(2):22 -30.

5. Ogun G, Bejide R. "Cervical Cancer in Nigeria, Still a Dismal Story: the Poor State of Cervical Cytology Screening. UICC World Cancer Congress. Washington DC, USA; 2006. p. 50-4.

6. Ajenifuja KO, Gage JC, Adepiti AC, Wentzensen N, Eklund C, Reilly M, et al. A Population-Based Study of Acetic Acid (VIA) for Cervical Screening in Rural Nigeria. Int J Gynecol Cancer. 2013;23(3):507-12. 
7. World Health Organization (WHO). Prevention of cervical cancer through screening using visual inspection with acetic acid (VIA) and treatment with cryotherapy. Nigeria: WHO; 2012 p. 1-33.

8. Sritipsukho P, Thaweekul Y. Accuracy of visual inspection with acetic acid (VIA) for cervical cancer screening: a systematic review. J Med Assoc Thai. 2010;93(7):254-61.

9. Albert SO, Oguntayo OA, Samaila MOA. Comparative study of visual inspection of the cervix using acetic acid (VIA) and Papanicolaou (Pap) smears for cervical cancer screening. Access. 2012;6(262):1-8.

10. Dianne M, Clement AO, Mirabal Y, Guillaud M, Oyedunni SA, Oladepo $\mathrm{O}$, et al. Knowledge dissemination and evaluation in a cervical cancer screening implementation program in Nigeria. Gynecol Oncol. 2007;107(1):196-207.

11. Adewole IF, Benedet JL, Crain BT, Follen M. Evolving a strategic approach to cervical cancer control in Africa. Gynecol Oncol. 2005;99(3):20912.

12. Abimbola O. cervical cancer and its control in Nigeria: challenges and the way forward. KIT (Royal Tropical Institude) Development, Policy and Practice/Vrije Universiteit Amsterdamm; 2008. p. 164.

13. Anorlu RI. Cervical cancer: the sub-Saharan African perspective. Reprod Health Matters. 2008;16(32):419.

14. Sankaranarayanan R, Budukh AM, Rajkumar R. Effective screening programmes for cervical cancer in low- and middle-income developing countries. Bull World Health Organ. 2001;79(10):954-62.

15. De Freitas AC, Gurgel APAD, Chagas BS, Coimbra EC, Do Amaral CMM. Susceptibility to cervical cancer: An overview. Gynecologic Oncology. 2012. p. 304-11.

16. Sankaranarayanan R, Shastri SS, Basu P, Mahé C, Mandal R, Amin G, et al. The role of low-level magnification in visual inspection with acetic acid for the early detection of cervical neoplasia. Cancer Detect Prev. 2004;28(5):345-51.

17. Awodele O, Adeyomoye A, Awodele DF, Kwashi V, Awodele IO, Dolapo DC. A study on cervical cancer screening amongst nurses in Lagos University Teaching Hospital, Lagos, Nigeria. J Cancer Educ. 2011;26(3):497-504.

18. Akinwuntan AL, Adesina OA, Okolo CA, Oluwasola OA, Oladokun A, Ifemeje AA, et al. Correlation of cervical cytology and visual inspection with acetic acid in HIV-positive women. J Obstet Gynecol. 2008;28(6):638-41.

19. Balogun MR, Odukoya OO, Oyediran M a, Ujomu PI. Cervical cancer awareness and preventive practices: a challenge for female urban slum dwellers in Lagos, Nigeria. Afr J Reprod Health. 2012;16:7582.

20. WHO. Cervical Cancer Screening in Developing Countries. 2002 p. 13-36.

21. Bruni L, Barrionuevo-Rosas L, Serrano B, Brotons M, Albero G, Cosano R, et al. Human Papillomavirus and Related Diseases in the World. Summary Report. 2014 p. 1-146.

22. Akinola OI, Fabamwo AO, Oshodi YA, Banjo AA, Odusanya O, Gbadegesin A, et al. Efficacy of visual inspection of the cervix using acetic acid in cervical cancer screening: a comparison with cervical cytology. J Obstet Gynecol. 2007;27(7):703-5.

23. Abdel-Hady E-S, Emam M, Al-Gohary A, Hassan M, Farag MK, Abo-Elkheir M. Screening for cervical carcinoma using visual inspection with acetic acid. Int J Gynecol Obstet. 2006;93(2):118-22.

24. Sadan O, Schejter E, Ginath S, Bachar R, Boaz M, Menczer J, et al. Premalignant lesions of the uterine cervix in enlarge cohort of Israeli Jewish women. Arch Gynecol Obs. 2004;269(3):188-91.

25. Swende T, Jogo A, Ageda B. Prevalence of Cervical Intraepithelial neoplasia among seronegative women in Markudi, Nigeria. Trop J Obs Gynecol. 2010;27(1):19-22.

26. Ahmed S, Avidimine S, Abu T, Oguntayo A, Sabitu K. Cervical dysplastic changes in women of reproductive age in Zaria, Northern Nigeria. Trop J Obstet Gynaecol. 2010;27(1):1-8.

27. Oguntayo O, Samaila M. Prevalence of cervical intraepithelial neoplasia in Zaria. Ann Afr Med. 2010;9(3):194-5.

28. Sherigar B, Dalal A, Durdi G, Pujar Y, Dhumale H. Cervical cancer screening by visual inspection with acetic acid - interobserver variability between nurse and physician. Asian Pacific $\mathbf{J}$ Cancer Prev. 2010;11(2):323-6.

29. Sankaranarayanan R, Wesley RS. A Practical Manual on Visual Screening for Cervical Neoplasia. Lyon: IARC Press; 2003:1-14.

30. Denny L. Cervical cancer in South Africa: An overview of current status and prevention strategies. CMEN. 2010;28(2):4-15.

Cite this article as: Abiodun $\mathrm{AB}$, Durodola $\mathrm{AO}$, Ajani MA, Amole IO, Abiodun AD, Oluwasola TAO. Comparative efficacy of visual inspection with acetic acid versus cytology for cervical cancer screening in Ogbomoso, Nigeria. Int J Reprod Contracept Obstet Gynecol 2017;6:3742-7. 